\title{
La remisión de la situación de Venezuela a la Corte Penal Internacional ¿Una medida efectiva o efectista por parte de los Estados Americanos? ${ }^{1}$
}

\section{The referral of the situation in Venezuela to the International Criminal Court. A sensationalist rather than an effective measure taken by the American States?}

\section{Claudia Cárdenas Aravena}

ccardenas@derecho.uchile.cl

Licenciada en Ciencias Jurídicas y Sociales por la Universidad de Chile, Magistra legum y Doctor iuris por la Humboldt-Universtät zu Berlin. Profesora asociada del Departamento de Ciencias Penales de la Universidad de Chile.

Resumen: La remisión de la situación de Venezuela a la Corte Penal Internacional por parte de varios Estados americanos, partes del Estatuto de Roma el 27 de septiembre recién pasado, pasado generó la atención de la prensa en los países de la región. El texto explica las limitadas consecuencias jurídicas efectivas de la sola remisión para el devenir del procedimiento; lo mismo que expone lo que los Estados efectivamente interesados en hacer funcionar el sistema de justicia penal internacional pueden hacer para demostrar su compromiso, que no es otra cosa que ejercer su jurisdicción sobre los crímenes cometidos y cooperar efectivamente con otras jurisdicciones.

Palabras claves: Corte Penal Internacional, remisión, Venezuela.

\begin{abstract}
The referral of the situation in Venezuela to the International Criminal Court by a group of American States, all Parties to the Rome Statute on the last 27th September has been reported by press of the countries in the region. The text explains that the limited legal consequences of the sole referral regarding the progression of the procedure. At the same time, it exposes what the States which are effectively interested in support the functioning the international criminal justice system could do in order to demonstrate their commitment, which is nothing else than exercise their jurisdiction over the crimes committed, and cooperate effectively with other jurisdictions..
\end{abstract}

Key words: International Criminal Court, Referral, Venezuela.

$1 \quad$ Artículo enviado el 30.11.2018 y aceptado el 04.12.2018.

Número de página no utilizable para citar




\section{Análisis}

La situación en Venezuela es objeto de preocupación desde hace ya varios años, al menos en el ámbito latinoamericano. No ha hecho falta interesarse demasiado por lo que acaece fuera de nuestras fronteras para enterarse. En años recientes son ya cuatro los informes del Secretario General sobre la situación en Venezuela. Incluso, el 14 de septiembre recién pasado, el Secretario General de la OEA, Luis Almagro, llegó a declarar que "no se debe descartar una intervención militar en Venezuela". ${ }^{2}$ La crisis - por su magnitud- nos ha visitado a domicilio, tanto en la forma de contingente migratorio de personas que buscan una mejor vida fuera de las fronteras de ese Estado como también en forma de viajes de denuncia de familiares de algunos de los perseguidos más prominentes del régimen de Maduro.

Así y todo, con Venezuela, como ocurre con otras situaciones de violaciones de derechos preocupantes a nivel global, el repudio no ha sido generalizado ni uniforme. Fue inicialmente más fuerte en los sectores tradicionales de derecha, para avanzar paulatinamente hacia el centro y parte de la izquierda, dado el signo político del régimen de Maduro. Lamentablemente, lo inverso se nota cuando el fenómeno tiene el signo político opuesto, como ha ocurrido con el matizado repudio que han recibido, por ejemplo, las declaraciones de Bolsonaro a favor de la tortura o menospreciando severamente a grupos de la población del Estado en el que ha sido elegido como Presidente. ${ }^{3}$

El presente texto está dedicado en particular a una de las medidas tomadas recientemente respecto de la situación en Venezuela. Se trata de la remisión que varios jefes de gobierno americanos, en conjunto, realizaran de la situación de Venezuela ante la Corte Penal Internacional. Esa remisión tuvo en su momento una importante cobertura mediática, en circunstancias de que lamentablemente no es por si misma idónea para ayudar a mermar el sufrimiento del pueblo venezolano, según paso a explicar a continuación.

La Corte Penal Internacional ha venido monitoreando la situación de Venezuela desde los primeros años de su quehacer. Así, mantuvo abierto un primer examen preliminar hasta el 9 de febrero de 2009, fecha en que informó que no encontraba mérito suficiente como para solicitar la apertura de una investigación en esa situación, por lo que cerraba el examen preliminar, sin

2 "OEA: No se debe descartar "intervención militar" en Venezuela para "derrocar" a Maduro", http://t13.cl/270305 [consulta 4.dic.2018].

3 "Jair Bolsonaro gana en Brasil: 7 frases que reflejan el pensamiento político, social y económico del nuevo presidente electo“, https://www.bbc.com/mundo/noticias-america-latina-45969725 [consulta 4.dic.2018]. 
perjuicio de quedar abierta la posibilidad de una reconsideración de su decisión en caso de allegarse nuevos antecedentes. ${ }^{4}$

El 8 de febrero de este año 2018, la Fiscalía de la Corte Penal Internacional volvió a abrir un examen preliminar en la situación de Venezuela, proprio motu. Este examen abarca crímenes que se hayan cometido por lo menos desde abril de 2017, en contexto de protestas y la agitación política relacionada. En particular, se está examinando el uso excesivo de la fuerza para dispersar y desactivar manifestaciones, y la privación de libertad de opositores o personas a las que se asume opositoras, parte de los cuales habrían sido seriamente maltratados. Por otra parte, también se tiene información de que, algunos de los grupos de protestantes han hecho uso de la violencia contra miembros de las fuerzas de seguridad, resultando también algunos de sus miembros muertos o heridos. ${ }^{5}$ Habiendo ratificado Venezuela el Estatuto de la Corte Penal Internacional en junio del año 2000, la Corte puede ejercer su jurisdicción desde la entrada en vigor del tratado, esto es el 1 de julio del año 2002, de acuerdo al artículo 11 de su Estatuto.

De lo anterior se desprende que el 27 de septiembre de 2018, cuando seis Estados americanos partes del Estatuto de Roma (Argentina, Canadá, Chile, Colombia, Paraguay y Perú) remitieron conjuntamente la situación de Venezuela a la Corte Penal Internacional, ${ }^{6}$ su Fiscalía ya la venía examinando hacía meses, basándose en las comunicaciones que había recabado. En el transcurso del examen preliminar había recibido, en mayo de 2018, un informe de la Secretaría General de la Organización de Estados Americanos sobre la posible comisión de crímenes de lesa humanidad en Venezuela (OEA, 2018), que se basa en el informe de un panel de expertos. ${ }^{7}$

Como es evidente que el procedimiento ante la Corte Penal no fue puesto en marcha por los Estados remitentes (que es el efecto usual que tienen las remisiones de Estados partes en el sistema del Estatuto de Roma de acuerdo a lo previsto en su art. 14), sino que el examen preliminar ya estaba puesto en marcha por la propia Fiscalía, vale la pena preguntarse si la medida tiene algún efecto práctico en beneficio de las personas víctimas de la violencia.

La etapa en la que está ahora el procedimiento, la de examen preliminar, no se ve alterada por el solo hecho de la remisión. Como ya estaba en marcha, seguirá las etapas que tiene prefijadas de acuerdo al instrumento de política publicado por la Fiscalía (Corte Penal Internacional, 2013), y que son -en lo principal- un espejo de los requisitos que establece el artículo 53.1 del Estatuto

4 Corte Penal Internacional, "Preliminary examination. Venezuela", https://www.icccpi.int/venezuela/Pages/default.aspx [consulta 4.dic.2018].

5 Corte Penal Internacional, "Preliminary examination. Venezuela", https://www.icc-cpi.int/venezuela [consulta 4.dic.2018].

6 "Presentación de varios Mandatarios latinoamericanos a la Fiscal de la Corte Penal Internacional", 25 de septiembre del 2018, https://cancilleria.gob.ar/userfiles/prensa/26-09-18_cpi_venezuela.pdf [consulta 4.dic.2018].

7 OEA, 'Panel de Expertos Internacionales Independientes encuentra 'fundamento suficiente' de crímenes de lesa humanidad en Venezuela", 29 de mayo de 2018, http://www.oas.org/es/centro_noticias/comunicado_prensa.asp?sCodigo=C-031/18 [consulta 4.dic.2018]. 
de Roma que la Fiscalía valore si hay un fundamento razonable para abrir una investigación, esto es: debe examinarse, sucesivamente, si hay fundamento razonable para creer que se han cometido crímenes de competencia de la Corte, si de la información que se recaba resulta que habría potenciales casos admisibles ante la Corte y si no hay razones para creer que una investigación no redundaría en interés de la justicia.

De lo anterior resulta que más importante que el hecho de la remisión hubiera sido que ella fuera acompañada de antecedentes nuevos, concretos y útiles para el examen en curso, que los países que remitentes hubieran podido aportar para que la Fiscalía tenga antecedentes plausibles que le permitan avanzar en las diversas fases de su examen preliminar. A lo menos en lo que es público pareciera no ser el caso, ya que la remisión no contiene una lista de documentos que se anexen, y en su texto la referencia a hechos se basa en el informe de la OEA, que estaba disponible para la Fiscalía de la Corte desde mayo de 2018. El colaborar para allegar antecedentes relevantes, si bien no requeriría de una remisión, podría tener gran relevancia para hacer exitoso el examen preliminar y acortar su duración, que de acuerdo al entendimiento de la Fiscalía de la Corte entiende no tiene plazo máximo. Piénsese que la situación de Colombia -uno de los remitentes de la situación de Venezuela- está en examen preliminar desde junio de 2004.

Ahora bien, de llegar a terminarse el examen preliminar arribando la Fiscalía a la convicción de que hay mérito para iniciar una investigación, si podría haber una diferencia procesal basada en el hecho de la remisión, ya que cuando la Fiscalía ha actuado de proprio motu debe solicitar la autorización de la Sala de Cuestiones Preliminares para iniciar una investigación formal, en tanto que si la situación ha sido remitida por un Estado parte (o por varios, como en este caso), puede abrirla sin necesidad de dicha autorización (art. 53.1, al final, del Estatuto de Roma), bastando solo que comunique que la ha abierto, siendo la fecha de la apertura la de esa comunicación. Con todo, no es el trámite de la autorización por la Sala de Cuestiones Preliminares lo que hace que los procesos ante la Corte sean más o menos ágiles y efectivos: la clave para ello está más bien en la cooperación que los Estados le den a la Corte Penal Internacional y en cómo los Estados se van comportando. Esto se explica porque, aun después de abierta la investigación, la Corte depende de la cooperación que le brinden los Estados para recabar evidencias, pues no cuenta con una policía judicial, ni con imperio para llevar adelante actuaciones directamente en el territorio de Estados sin su cooperación. De allí que el Estatuto dedique toda su parte IX a cooperación y asistencia judicial. Además, en cualquier caso, la Fiscalía tiene por política de persecución enfocarse solo en quienes tienen mayor responsabilidad en los crímenes más graves (Corte Penal Internacional, 2006: 5). Así, lo clave será que la Fiscalía pueda obtener a la brevedad información que le permita prever que podrá llevar adelante casos exitosos contra los más altos responsables. Esto será crucial sobre todo de cara a las exigencias de mayor acuosidad y detalle ya desde etapas iniciales del procedimiento, que podría tener como efecto la resolución de la Sala 
de Apelaciones en el caso Bemba del 8 de junio del 2018 (parr. 74 y ss.). ${ }^{8}$ Entonces, para saber a ciencia cierta si la remisión fue una medida efectiva o efectista todavía nos resta esperar: si junto a la declaración de remisión los Estados mantienen flujos de cooperación permanente con la Fiscalía de la Corte, que le permita tener información suficiente para avanzar en su examen preliminar, para luego iniciar juicios y en definitiva lograr una o más sentencias, las medida podrá calificarse ex post de efectiva, sobre todo si va acompañada del juzgamiento de hechos en los territorios de los países que se muestran interesados en colaborar al buen funcionamiento del sistema de justicia internacional, atendido a que la Corte Penal Internacional no pretenderá juzgar sino a los más altos responsables respecto de cuya responsabilidad pueda obtener evidencia de calidad.

En cambio, si es que la remisión se queda solo en el documento enviado y la noticia de ese día, no pasará de recordarse por la anécdota de que constituye dos estrenos a la vez: por una parte, es la primera vez que varios Estados partes realizan una remisión en conjunto; y por otra es la primera remisión en la historia de la Corte Penal Internacional que no constituye una autoremisión. Así, las situaciones de Uganda, República Democrática del Congo, República Centroafricana I y II y Mali, fueron esos Estados -todos africanos- los que remitieron las situaciones ocurridas en sus propios territorios a la Corte Penal Internacional. Lamentablemente, la regla en estos casos ha sido que ha sido justamente esa -la remisión- la principal medida que han tomado esos Estados para la persecución y castigo de los graves crímenes cometidos. Es de esperar que en esta ocasión los Estados remitentes, que están objetivamente en un mejor pie de estabilidad y recursos que aquellos otros Estados que anteriormente remitieron situaciones a la Corte Penal Internacional, lo hagan en un verdadero espíritu de fortalecer el sistema de justicia penal internacional. Esto requiere tener en consideración su naturaleza complementaria, entendiendo que la Corte que en ningún caso pretende reemplazar, sino suplir solo donde sea absolutamente necesario, el ejercicio de la jurisdicción de los Estados, siendo ellos, como lo recuerda el Estatuto en el párrafo sexto de su preámbulo, los primeros llamados a ejercer jurisdicción cuando constaten la existencia de crímenes contra el derecho internacional. Lo coherente sería, entonces, hacer todo lo posible para colaborar con la Corte e instar, en paralelo, a que se inicien investigaciones en sus propias jurisdicciones.

Recién si se superan con éxito las etapas del examen preliminar y se abre una investigación la Fiscalía -y nadie más- decidirá a quien(es) imputar de acuerdo a la evidencia que tenga. Lo que debieran hacer Estados que, como los remitentes, están convencidos de que en el territorio de Venezuela se han cometidos crímenes de lesa humanidad es, en primer lugar, investigar y perseguir por si mismos estos delitos, y -para los casos en los que no puedan hacerlo por si mismos-, cooperar con los Estados que sí lo hagan y con la Corte Penal en todo lo necesario para asegurar una exitosa investigación, juicio y cumplimiento efectivo de las condenas.

8 Corte Penal Internacional, Sala de Apelaciones, caso Bemba, 8 de junio de 2018, https://www.icccpi.int/CourtRecords/CR2018_02984.PDF [consulta 4.dic.2018]. 
Quedarse solo en el gesto formal de la remisión, si bien puede generarles ventaja mediática actual de aparecer colaborando en algo a la justicia penal internacional y la eventual futura ventaja mediática de poder culpar a un tercero si el proceso no avanza "a pesar" de su gesto político, no sirve en realidad para acercar de modo relevante la investigación y juzgamiento de los delitos en esta situación.

El solo gesto formal de la remisión de la situación de Venezuela a la Corte Penal Internacional en 27 de septiembre pasado, de no ir acompañado de otras acciones más sustanciales, no solo sería relativamente neutral a los esfuerzos de la justicia penal en la materia, peor aún, puede contribuir a crear falsas expectativas en las personas, cuya defraudación hace a la postre un flaco favor a la tan necesaria como vilipendiada justicia penal internacional. Espero no sea demasiado cándido otorgar el favor de la duda a los Estados, dándoles todavía la ocasión de demostrar mediante acciones más efectivas hasta donde llega su real compromiso con la investigación y persecución de los crímenes a los que se refirieron en su remisión.

\section{Referencias bibliográficas}

Corte Penal Internacional, Oficina del Fiscal (2006). Report on Prosecutorial Strategy, 14 de septiembre del 2006, https://www.icc-cpi.int/NR/rdonlyres/D673DD8C-D427-4547BC69-2D363E07274B/143708/ProsecutorialStrategy20060914_English.pdf [consulta 4.dic.2018].

Corte Penal Internacional (2013). Documento de política general sobre exámenes preliminares, noviembre de 2013, https://www.icc-cpi.int/iccdocs/otp/OTP-Policy_Paper_Preliminary_ Examinations_2013-SPA.pdf [consulta 4.dic.2018].

Organización de Estados Americanos (2018). Informe de la Secretaría General de la Organización de los Estados Americanos y del Panel de Expertos Internacionales Independientes sobre la posible comisión de crímenes de lesa bumanidad en Venezuela. Washington D.C., 29 de mayo de 2018, http://www.oas.org/documents/spa/press/Informe-Panel-Independiente-VenezuelaES.pdf [consulta 4.dic.2018].

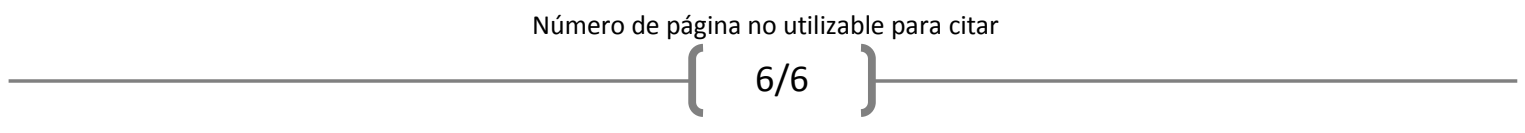

